\title{
Thermal modeling of the TMT Telescope
}

\section{Myung Cho, Andrew Corredor, Konstantinos Vogiatzis, George Angeli}

Myung Cho, Andrew Corredor, Konstantinos Vogiatzis, George Angeli, "Thermal modeling of the TMT Telescope," Proc. SPIE 8336, Integrated Modeling of Complex Optomechanical Systems, 83360V (10 November 2011); doi: $10.1117 / 12.915634$

SDIE Event: Integrated Modeling of Complex Optomechanical Systems, 2011, Kiruna, Sweden 


\title{
Thermal Modeling of the TMT Telescope
}

\author{
Myung Cho ${ }^{* 1}$, Andrew Corredor ${ }^{2}$, Konstantinos Vogiatzis $^{3}$, George Angeli $^{3}$ \\ ${ }^{1}$ GSMT Program Office, National Optical Astronomy Observatory \\ 950 N. Cherry Ave., Tucson, AZ 85719 \\ ${ }^{2}$ Aerospace and Mechanical Engineering Department, University of Arizona, Tucson, AZ 85721 \\ ${ }^{3}$ TMT Project Office, California Institute of Technology, Pasadena, CA 91125
}

\begin{abstract}
Thermal modeling of the Thirty Meter Telescope (TMT) was conducted for evaluations of thermal performances by finite element (FE) and optical analysis tools. The thermal FE models consist of the telescope optical assembly systems, instruments, laser facility, control and electronic equipments, and telescope structural members. A three-consecutive-day thermal environment data was implemented for the thermal boundary created by Computational Fluid Dynamics (CFD) based on the environment conditions of the TMT site. Temporal and spatial temperature distributions of the optical assembly systems and the telescope structure were calculated under the environmental thermal conditions including air convections, conductions, heat flux loadings, and radiations. With the calculated temperature distributions, the thermoelastic analysis was performed to predict thermal deformations of the telescope structure and the optical systems. The line of sight calculation was made using the thermally induced deformations of the optics and structures. Merit function routines (MFR) were utilized to calculate the Optical Path Difference (OPD) maps after repositioning the optics based on a best fit of M1 segment deformations. The goal of this thermal modeling is to integrate the mechanical and optical deformations in order to simulate the thermal effects with the TMT site environment data from CFD.
\end{abstract}

Keywords: Telescope structure thermal analysis, TMT site environment data, thermal response, Merit function calculations, thermo-elastic analysis, TMT telescope.

\section{INTRODUCTION}

Large telescopes commonly require high fidelity modeling to predict the performances. For ground-based extremely large telescopes, thermal modeling of the telescope systems is highly inter-related with many design parameters and environments; therefore, it is sophisticated in predicting the performances. Integrated modeling of extremely large telescopes is highly demanding. For such telescopes, balancing the performance between wind buffeting and mirror and dome seeing has always been one of the challenging requirements to fulfill scientific goals ${ }^{[1]}$. A three-year environmental measurement of the TMT baseline site ${ }^{[7]}$ and Computational Fluid Dynamics (CFD) techniques provide the thermal environment parameters surrounding the TMT structure. For thermal finite element models, the environmental record and CFD predictions provide expected flow fields and thermal boundary conditions in terms of ambient air profiles, convection coefficients, heat fluxes, and radiation properties. These parameters were implemented to predict thermal responses and thermal deformations of the TMT optics and the structure ${ }^{[9]}$.

TMT will achieve excellent image quality for both seeing limited and adaptive optics (AO) modes of operation. The seeing limited mode is evaluated with the normalized point-source sensitivity (PSSN) ${ }^{[16]}$. For primary mirror control system (M1CS), AO performance is achieved when seeing-limited performance is achieved. Overall thermal modeling data flow schematic in the TMT is shown in Figure 1. Modeling framework requires interaction matrices that are inputs to or outputs from several other interface modules and analyses. Certain analysis often uses a quasi-static model, whereas the rest require varying degrees of fidelity of dynamic modeling in the Monte-Carlo Framework.

*mcho@noao.edu; phone 1520 318-8544; fax 1520 318-8424; www.noao.edu

Integrated Modeling of Complex Optomechanical Systems, edited by Torben Andersen, Anita Enmark, Proc. of SPIE Vol. 8336, 83360V · (C) 2011 SPIE · CCC code: 0277-786X/11/\$18 · doi: 10.1117/12.915634 
The main philosophy in this thermal modeling is to develop appropriate models to address specific required operational scenarios. The thermal results from the operation will be able to provide a telescope thermal control strategy, confirm error budget allocation in telescope pointing, M1CS actuator stroke, Secondary mirror (M2) hexapod range, and other thermally induced deformations in the telescope structure members. In addition, these thermal results are to be utilized to provide input to wavefront control strategy and TMT optics performance modeling.

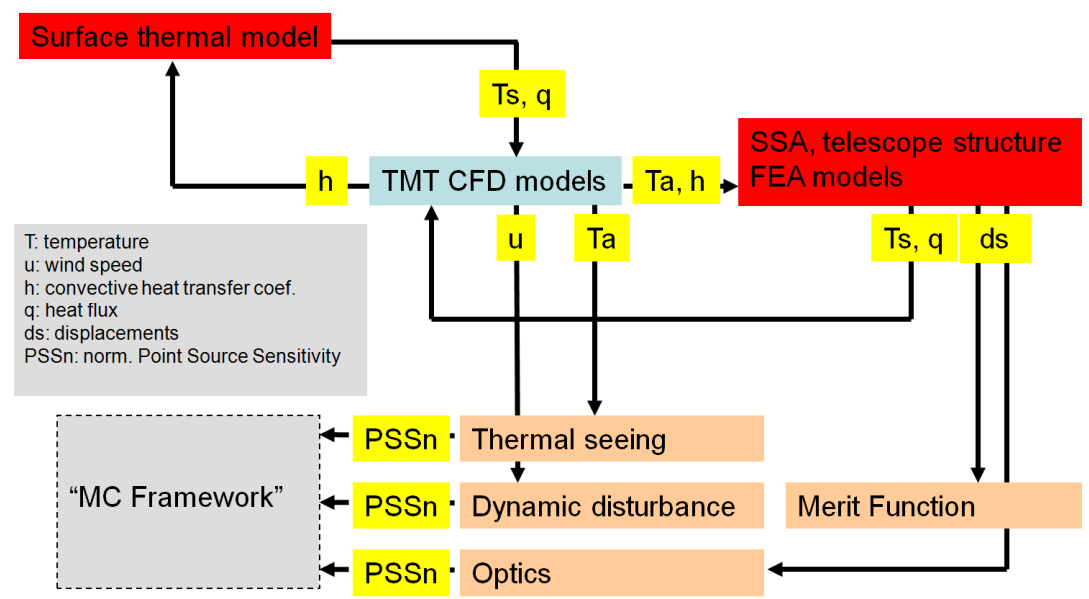

Fig. 1. Data flow in thermal modelling in Monte-Carlo Framework.

Thermal analysis for the Thirty Meter Telescope Structure was performed using finite element analysis in ANSYS. In such analysis, the entire telescope structure was modeled and analyzed under different thermal loads. The temperature distribution on the model was calculated using predetermined heat loads for both Horizon pointing $\left(\right.$ Zenith angle $=90^{\circ}$, Daytime Maintenance/Service Configuration) and Observation configurations (Zenith Angle $=32^{\circ}$, Nighttime Observing Configuration). The present analysis was performed in order to predict the thermal responses of the telescope structure during a 3 day/night period of continuous operation.

The thermal finite element models developed were based on the dimensions and physical properties of the structural version of the telescope finite element model created by Empire Dynamic Structures, Ltd ${ }^{[11]}$. The telescope models analyzed in this report incorporate the entire elevation structure, the azimuth structure, the foundation pier structure and the Nasmyth platforms as shown below in Figures 2. (a) and (b). Moreover, the major structural components in the telescope and the instruments located on both Nasmyth platforms were modeled in order to analyze the thermal effects on the structure due to the heat conductive, heat convective and heat radiative loads.

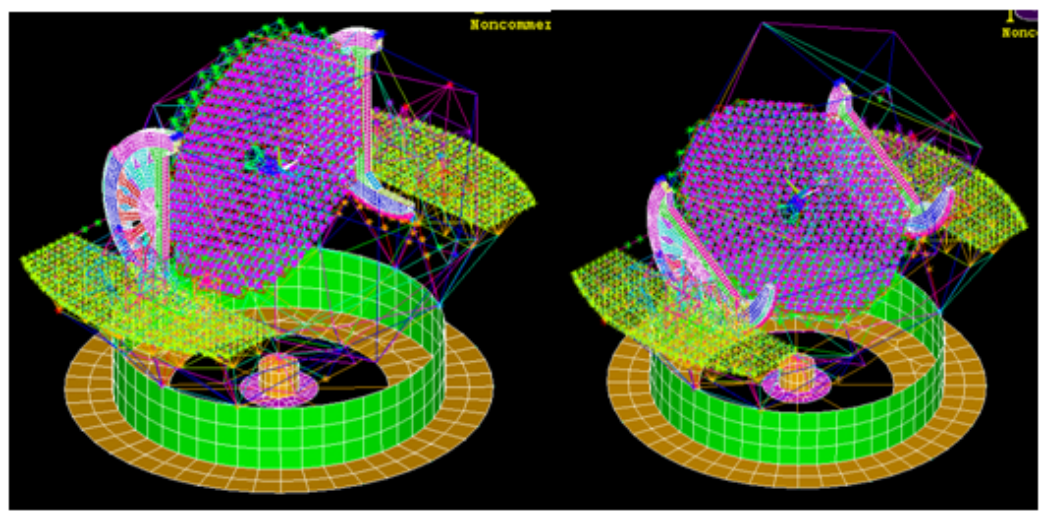

(a)

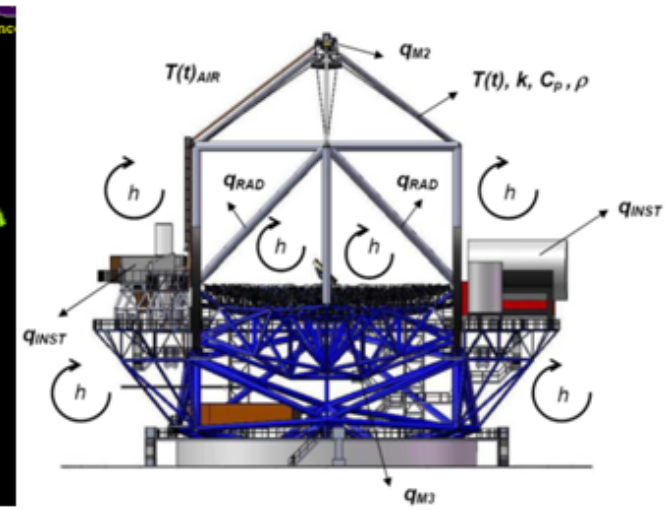

(c)

Fig. 2. (a) FEM Telescope Structure used for daytime operation (Zenith angle $=90^{\circ}$ ); (b) FEM Telescope Structure used for night time operation (Zenith angle $\left.=32^{\circ}\right)$; (c) Thermal environment of the telescope. 
The thermal environment of the telescope is shown in Figure 2(c). The boundary conditions specified on the telescope model are the following:

- Heat dissipation from M1 actuators, instruments and the heat dumps located on the Nasmyth platforms.

- Convection of air on the telescope structure's surfaces excluding the foundation pier.

- Radiation exchange from surface to surface, and radiation losses to the environment.

The heat dissipated from the Secondary Mirror (M2), the Tertiary Mirror (M3) and the hydrostatic bearings on the telescope structure have also been included in this analysis. The variables in the thermal environment of the TMT are as follows:

$h(x, y, z, t):$ Heat transfer coefficient (varies depending on time and location)

$q_{I N S T}$ : Instrument heat dissipation

$q_{M I}:$ M1 Heat dissipation

$q_{M 2}:$ M2 Heat dissipation

$q_{M 3}:$ M3 Heat dissipation

$q_{R A D}$ : Radiation Surface to surface

$q_{\text {H.D.: }}$ : Heat dumps dissipation

$q_{S K Y}$ : Radiation losses (Night Sky)

$T(x, y, z, t)_{A I R}$ : Air Temperature

$T(x, y, z, t)$ : Surface temperature

With finite element methods, detailed analyses have been performed on the telescope. The thermal response of the finite element thermal model was calculated for both observation and maintenance/service configurations during the three day and night period of operation.

\section{THERMAL ANALYSIS}

\subsubsection{Thermal Loads and Boundary Conditions}

In order to evaluate the thermal response of the telescope appropriately, the entire telescope structure model utilizes well defined telescope operation boundary conditions and the site environment conditions. Such conditions were air convection on the telescope's surfaces; heat dissipation from M1 actuators, the instruments and heat dumps on the Nasmyth platform; radiation exchange from surface to surface and radiation losses to the environment. Furthermore, extended thermal analyses have been conducted in order to quantify the thermal results.

A three-consecutive-day thermal environment data was implemented to predict thermal responses of the telescope structure. The thermal environment data and thermal boundary condition was created by CFD based on the environment conditions of the TMT site ${ }^{[14]}$. Daytime environment data was simulated by CFD analysis when the telescope structure and the air inside the enclosure are controlled by air conditioner. In general, the ambient air temperatures and heat convection coefficients are parameterized to account for the average temperature of the previous night and predicted temperature of the following night. Nighttime environment data was also simulated by CFD analysis based on representative nights from the Stochastic Framework, or the Standard Year ${ }^{[14]}$. Stochastic Framework contains a 3-year record of environmental parameters, telescope orientations, and observing data ${ }^{[15]}$. The ambient air temperatures and heat convection coefficients were sampled at every two minutes over the telescope structure. In this paper, the following analyses were performed with the three-consecutive-day thermal environment data:

For each of the three days, thermal analysis was performed for Day and Night mode as follows:

- Case A: Daytime Mode - Combined thermal loads (Air convection and conduction)

- Case B: Nighttime Mode - Combined thermal loads (Air convection, Radiation and conduction)

\subsubsection{Air temperature variation}

Extensive CFD analyses have been performed to quantify air flows inside the enclosure. Moreover, some simulation schemes have been developed for the air temperature distribution around the telescope. For the Maintenance, Service, or 
day time Air Conditioning Configuration, the spatial variation of the air temperature occurs in three zones as depicted in Figure 3; in addition, the three time-dependent air temperature profiles used for the each daytime configuration are shown in Figures 4(a). Such profiles show the variation in air temperature during the 12.5 hour heat cycle.

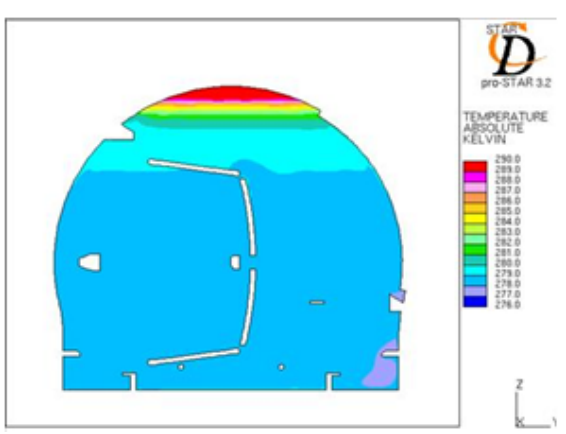

(a)

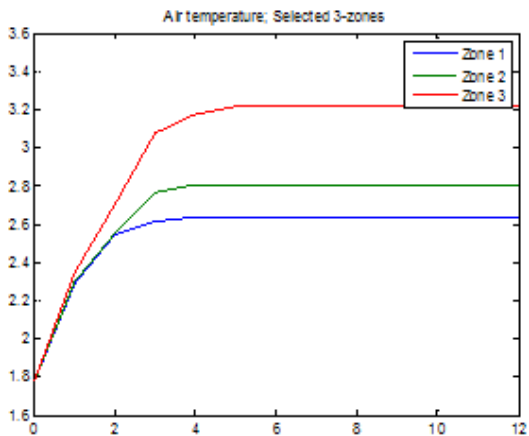

(b)

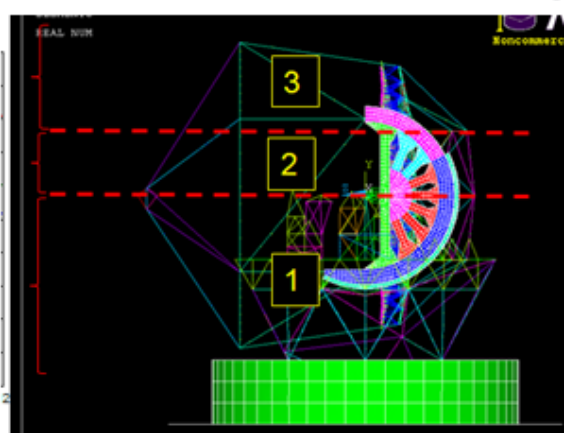

(c)

Fig. 3. Typical spatial and temporal variations of air temperature on TMT telescope structure, (a) Temperatures of stratified daytime air in enclosure; (b) Ambient air temperature in time, hours; (c) Three zones identified in finite-element model of telescope structure.

For the night-time mode, Observation Configuration, ambient air temperature profiles were implemented and applied on the telescope structure. The effects from the temporal and spatial variations of the air temperature on the telescope for each nighttime ( 11.5 hour heat cycle) configuration were evaluated. Typical temporal variation of the air temperature on the telescope for the second nighttime is depicted in Figure 4(b). In Figure 4(a) for the third day, two air conditioning predictions during the day time are shown for the third night operation. Thermal analysis was made for both predictions, and results were summarized for the Prediction: V2.

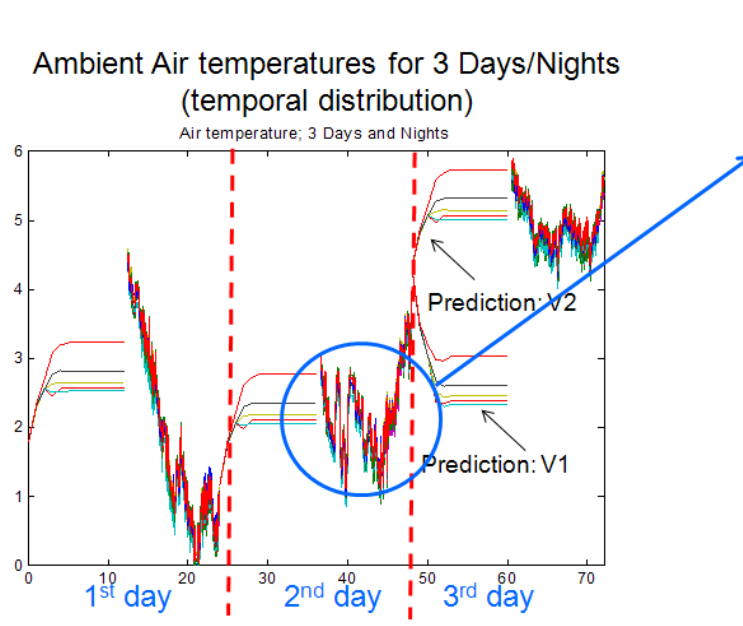

(a)

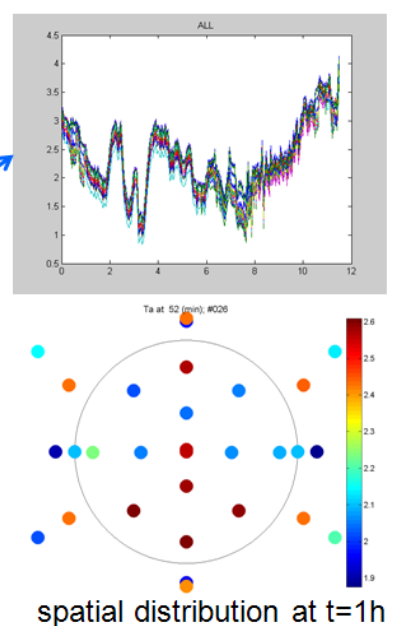

(b)

Fig. 4. Typical spatial and temporal variations of air temperature on TMT telescope structure, (a) Air temperature temporal distributions for 3 days and nights; (b) Ambient air temperature in time, hours for second night and Air temperature spatial distribution at 1 hour from the beginning of the second night.

\subsubsection{Conduction Analysis (Heat Dissipation)}

The conduction effects on the telescope were determined based on the heat dissipation from the instruments, the heat dumps located on the Nasmyth platforms, and the heat dissipated by the M1 actuators. Heat dissipations from M2, M3, and the hydrostatic bearings on the telescope structure were also included in the present analysis; they are additional loads from the previous thermal performance analysis. The heat dissipated by each component is listed in Table 1. It is noted that in both daytime and nighttime configurations, the heat flow values shown on Table 1 were assumed to be constant for the duration of the heat cycle.

Table 1: Heat Dissipation for Daytime and nighttime configurations (for M1, heat load of 5W/segment was applied). 


\begin{tabular}{|c|c|c|c|c|c|c|c|}
\hline \multirow[b]{2}{*}{ Item Name } & \multirow[b]{2}{*}{ Shape/Qty. } & \multirow[b]{2}{*}{ Volume } & \multirow[b]{2}{*}{$\begin{array}{l}\text { Surface } \\
\text { area }\left(m^{2}\right)\end{array}$} & \multicolumn{2}{|c|}{ Nighttime Heat Dumps } & \multicolumn{2}{|c|}{ Daytime Heat Dumps } \\
\hline & & & & $\begin{array}{l}\text { N AA } \\
\text { (kW) }\end{array}$ & $\begin{array}{l}\text { N AA from } \\
\text { Glyc (kW) }\end{array}$ & D AA (kW) & $\begin{array}{l}\text { D AA from } \\
\text { Glyc (kW) }\end{array}$ \\
\hline $\begin{array}{l}\text { NFIRAOS optical bench }\left(4^{*} 4^{*} 8\right) \\
\text { NFIRAOS electronics cabinet }\end{array}$ & Box & $\begin{array}{l}\text { Space envelope drawing } \\
3.7(\mathrm{~W}) \times 2(\mathrm{H}) \times 0.9(\mathrm{D})\end{array}$ & $\begin{array}{r}160.0 \\
25.1\end{array}$ & $\begin{array}{r}-1 \\
0.2\end{array}$ & $\begin{array}{r}0 \\
0.4\end{array}$ & $\begin{array}{r}-1 \\
0.2\end{array}$ & $\begin{array}{r}0 \\
0.4\end{array}$ \\
\hline IRMS/WIRC & Cylinder & 2 (Dia.) $\times 4(\mathrm{H})$ & 31.4 & 0.1 & & 0.1 & \\
\hline WIRC electronics cabinet & 3 & $1.8(\mathrm{~W}) \times 2(\mathrm{H}) \times 0.9(\mathrm{D})$ & 14.0 & & 0.09 & & 0.09 \\
\hline IRIS & Cylinder & 2 (Dia.) $\times 4(\mathrm{H})$ & 31.4 & 0.1 & & 0.1 & \\
\hline IRIS electronics cabinet & 4 & $2.4(\mathrm{~W}) \times 2(\mathrm{H}) \times 0.9(\mathrm{D})$ & 17.5 & & 0.25 & & 0.25 \\
\hline NIRES-B/NIRES-R & Cylinder & 1 (Dia.) $\times 1.5(H)$ & 6.3 & 0.1 & & 0.1 & \\
\hline NIRES electronics cabinet & 3 & $1.8(\mathrm{~W}) \times 2(\mathrm{H}) \times 0.9(\mathrm{D})$ & 14.0 & & 0.075 & & 0.075 \\
\hline $\begin{array}{l}\text { APS } \\
\text { APS electronics cabinet }\end{array}$ & Box & $\begin{array}{l}3(\mathrm{~W}) \times 1(\mathrm{H}) \times 4(\mathrm{D}) \\
1.2(\mathrm{~W}) \times 1.2(\mathrm{H}) \times 0.9(\mathrm{D})\end{array}$ & $\begin{array}{r}38.0 \\
7.2\end{array}$ & 0.1 & 0.25 & 0.1 & 0.25 \\
\hline MIRAO & & $\begin{array}{l}1.3(\mathrm{~W}) \times 2.85(\mathrm{H}) \times 2.2 \\
(\mathrm{D})\end{array}$ & 25.7 & 0.1 & & 0.1 & \\
\hline $\begin{array}{l}\text { MIRES } \\
\text { MIRAO/MIRES electronics } \\
\text { cabinet }\end{array}$ & Cylinder & $\begin{array}{l}1.5(\text { Dia. }) \times 3.8(\mathrm{H}) \\
1.8(\mathrm{~W}) \times 2(\mathrm{H}) \times 0.9(\mathrm{D})\end{array}$ & $\begin{array}{l}21.4 \\
14.0\end{array}$ & 0.1 & $\begin{array}{r}0.075 \\
0.1 \\
\end{array}$ & 0.1 & $\begin{array}{r}0.075 \\
0.1\end{array}$ \\
\hline $\begin{array}{l}\text { WFOS } \\
\text { WFOS electronics cabinet }\end{array}$ & Cylinder & $\begin{array}{l}7 \text { (Dia.) } \times 11.7(\mathrm{D}) \\
1.8(\mathrm{~W}) \times 2(\mathrm{H}) \times 0.9(\mathrm{D})\end{array}$ & $\begin{array}{r}334.1 \\
14.0\end{array}$ & 0.1 & 0.3 & 0.1 & 0.3 \\
\hline HROS & Box & $11(\mathrm{~W}) \times 4(\mathrm{H}) \times 10(\mathrm{D})$ & 388.0 & 0.1 & & 0.1 & \\
\hline HROS electronics cabinet & 3 & $1.8(\mathrm{~W}) \times 2(\mathrm{H}) \times 0.9(\mathrm{D})$ & 14.0 & & 0.75 & & 0.75 \\
\hline HROS enclosure cooling & & $2(\mathrm{~W}) \times 2(\mathrm{H}) \times 2(\mathrm{D})$ & 24.0 & & 0.25 & & 0.25 \\
\hline IRMOS & Cylinder & 4 (Dia.) x 5.9 (D) & 99.2 & 0.1 & & 0.1 & \\
\hline IRMOS meat locker & & $1(\mathrm{~W}) \times 2(\mathrm{H}) \times 2(\mathrm{D})$ & 16.0 & & 0.25 & & 0.25 \\
\hline IRMOS electronics cabinet & 7 & $4.3(\mathrm{~W}) \times 2(\mathrm{H}) \times 0.9(\mathrm{D})$ & 28.5 & & 0.75 & & 0.75 \\
\hline \multicolumn{4}{|l|}{ M1 } & & 2.5 & & 2.5 \\
\hline \multirow{3}{*}{\multicolumn{4}{|c|}{$\begin{array}{l}\text { M2 Cell } \\
\text { M2 Cell control } \\
\text { M2 Hexapod } \\
\text { M2 Hexapod control }\end{array}$}} & $\begin{array}{r}0.25 \\
0.3\end{array}$ & $\begin{array}{r}0.25 \\
0.3\end{array}$ & $\begin{array}{r}0.25 \\
0.3\end{array}$ & $\begin{array}{r}0.25 \\
0.3\end{array}$ \\
\hline & & & & 0.21 & 0.21 & 0.21 & 0.21 \\
\hline & & & & 0.3 & 0.3 & 0.3 & 0.3 \\
\hline \multirow{2}{*}{\multicolumn{4}{|c|}{$\begin{array}{l}\text { M3 Cell } \\
\text { M3 Cell control }\end{array}$}} & 0.25 & 0.25 & 0.25 & 0.25 \\
\hline & & & & 0.3 & 0.3 & 0.3 & 0.3 \\
\hline \multicolumn{4}{|l|}{ M3 Positioner } & 0.33 & 0.33 & 0.33 & 0.33 \\
\hline \multicolumn{4}{|l|}{ M3 Positioner control } & 0.3 & 0.3 & 0.3 & 0.3 \\
\hline \multicolumn{4}{|l|}{ Elevation Structure } & & 0.56 & & 0.56 \\
\hline \multicolumn{4}{|l|}{ Azimuth Bearings } & & 0.15 & & 0.15 \\
\hline LGF/LSE (AZ in -Y) & Box & Space envelope drawing & & 0.2 & 0.48 & 0 & 0.48 \\
\hline LGF/LSE (AZ in +Y) & Box & Space envelope drawing & & 0.2 & 0.48 & 0 & 0.48 \\
\hline \multicolumn{4}{|c|}{ LGF/LSE top end and BTO (with control) } & 0 & 0.13 & 0 & 0.13 \\
\hline
\end{tabular}

\subsection{Finite Element Models}

For temperature distribution of the Telescope structure, thermal finite element models were established using ANSYS. The beams, trusses, and supports of the telescope were modeled using thermal conductive elements (LINK33), and the C-Rings were modeled using thermal shell elements (SHELL 57). In addition to these elements, thermal convective (LINK32) and radiative (LINK31) elements were created in order to perform the convection and radiation analysis, respectively. Such link elements simplify the complexity of the analysis by allowing the input of surface convective and radiative areas, and emissivity coefficients without having to create solid models for the convective and radiative analyses. Additionally, a super-element (MATRIX50) was used in order to perform the radiation analysis between surfaces (C-Rings). The finite element models used in this analysis are shown in Figures 2(a) and (b). By ANSYS thermal analysis, the temperature distribution for each of the different cases described previously was calculated.

\subsection{Thermal Analysis Results - Daytime Configuration}

\subsubsection{Daytime Mode - Combined thermal loads (Air convection and conduction)}

The thermal response results obtained for a sample thermal analysis, Second Day Daytime mode (Case A), are presented in this section. In such case, the heat dissipation values from Table 1 were applied to the respective instruments, M1 actuators and heat dumps on the telescope model at telescope Zenith angle of 90 degrees. Moreover, air convection was applied on the Telescope's surfaces with different heat transfer coefficients depending on the spatial location. For the 
primary mirror support system (M1SS), five (5) heat transfer coefficients were implemented with values varying from 1 $\mathrm{W} / \mathrm{m}^{2}{ }^{\circ} \mathrm{C}$ to $3 \mathrm{~W} / \mathrm{m}^{2 \circ} \mathrm{C}$, as depicted in Figure 5 .

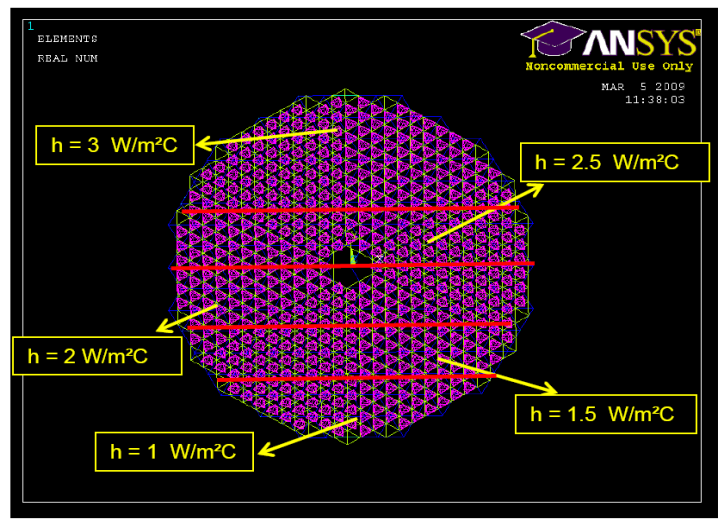

Fig. 5. Spatial distribution of heat transfer coefficient on M1SS

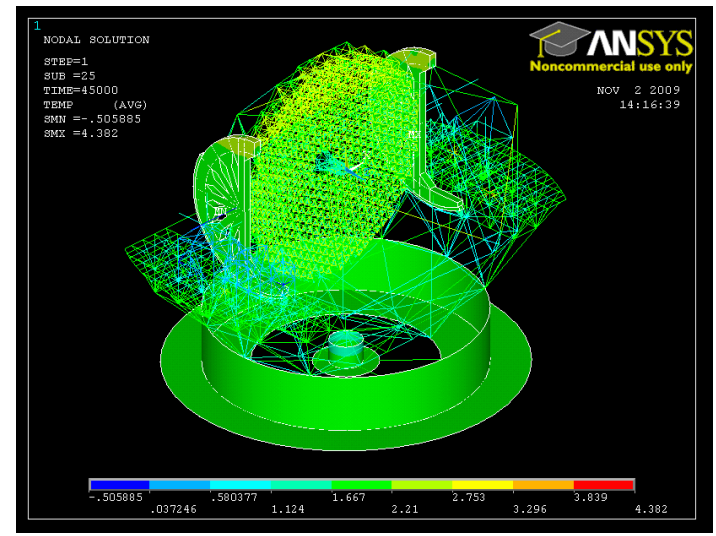

Fig. 6. Temperature Distribution (Case A of $2^{\text {nd }}$ day)

All the other components in the structure were assumed to have a heat transfer coefficient of $3 \mathrm{~W} / \mathrm{m}^{20} \mathrm{C}$. The air temperature profile described previously in section 2.1.2 and these heat transfer coefficients were used to obtain the temperature response for the telescope's daytime configuration (Day 2). The maximum and minimum temperature responses obtained for the telescope from the analysis were $4.38^{\circ} \mathrm{C}$ and $-0.505{ }^{\circ} \mathrm{C}$, respectively (Figure 6).

\subsubsection{Nighttime Mode - Combined thermal loads (Air convection, Radiation and conduction)}

In a similar manner, the thermal response obtained for a sample thermal analysis $\left(2^{\text {nd }}\right.$ Nighttime - Case B) is presented in this section. Here, heat dissipations from the instruments, M1 actuators and heat dumps on the structure were applied to the telescope model having a zenith angle of 32 degrees (Observation configuration). Moreover, Heat transfer coefficients and temperature values were implemented from CFD simulations; such data was utilized for the application of the air convection load on 30 different regions on the telescope. Some of these regions were identified and are shown in Figure 7(a). Additionally, the heat transfer coefficient temporal and spatial variations for each of the three nights of operation were implemented.

The night-time record is $11.5 \mathrm{~h}$ long and the temporal sampling rate is 2 minutes. A set of 30 key points were identified for the data interface between CFD model and FE models. The ambient air temperatures and convection coefficients temporal distributions were spatially mapped over the key points and then further interpolation was employed over the FE models. Figures 7(a) and (b) show the locations of these key points. They consist of 12 points on M1, one representative point on M2 and one on M3, one for each of the two elevation rings, 4 on the Nasmyth platforms, 4 on the telescope pier and 6 on the corners of the hex ring.
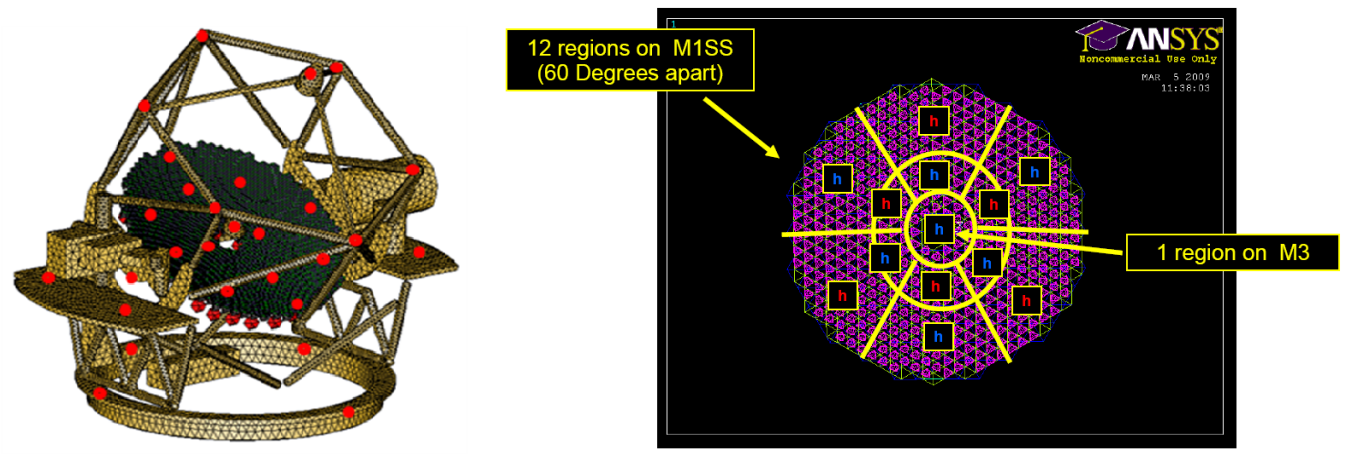

Fig. 7. (a) Telescope locations where ambient temperature and heat transfer coefficient are reported for FEA boundary conditions, (b) Specified air convection regions on M1SS. 
Additionally, the heat transfer coefficient temporal and spatial variations for each of the three nights of operation were implemented in the model. A typical variation for the second night is shown on Figure 8.

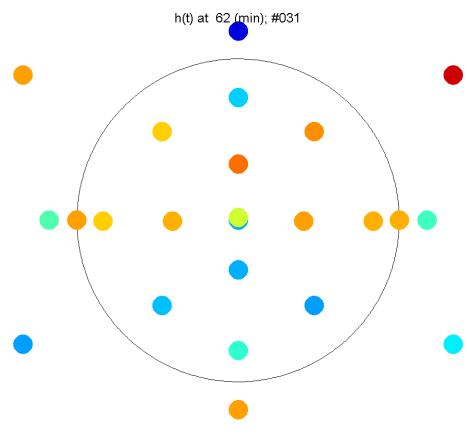

$h(t) 0-6$ hrs

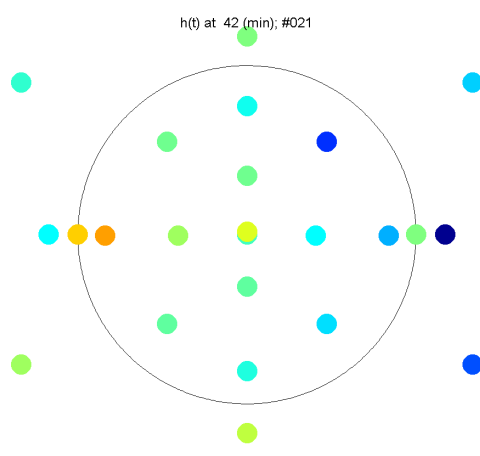

$6-9 \mathrm{hrs}$

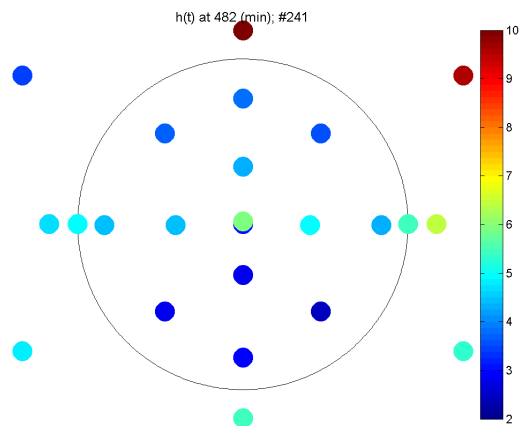

$9-11.5 \mathrm{hrs}$

Fig. 8. Temporal and spatial variation of heat transfer coefficient $\left(2^{\text {nd }} \mathrm{Night}\right)$

In addition to the convective and conductive conditions, radiation heat loads were applied on the telescope model. For this case the background temperature was assumed to be two degrees cooler than the air temperature $\left(\mathrm{T}=\mathrm{T}_{\text {air }}-2^{\circ} \mathrm{C}\right)$. Moreover, emissivity values were assigned to the components on the telescope; the following are their corresponding values:

- $\quad$ M1 Support Structure (M1SS): Front $\varepsilon=0.6$, Back $\varepsilon=1.0$, Intermediate $\varepsilon=0.8$

- $\quad$ Structure above M1, $\varepsilon=0.4$

- $\quad$ Structure behind M1SS, $\varepsilon=1.0$

- $\quad$ Nasmyth platform and instrument supports, $\varepsilon=0.8$

- Instrument Supports, $\varepsilon=1.0$

- Instruments, $\varepsilon=0.4$

- No Radiation Loads were applied on the concrete piers

Furthermore, radiative flux was applied on the top end of the telescope structure. Three sections were chosen on the model, and the corresponding values utilized for the radiative flux are as follows:

- M2: Q" $=-40 \mathrm{~W} / \mathrm{m}^{2}$ (Constant during period of operation)

- Diagonal Supports: $\mathrm{Q} "=-20 \mathrm{~W} / \mathrm{m}^{2}$ (Constant during period of operation)

- Hexagonal Truss: $\mathrm{Q} "=-4.5 \mathrm{~W} / \mathrm{m}^{2}$ (Constant during period of operation)

\subsubsection{Daytime/Nighttime Modes - Combined thermal loads (Air convection, Radiation and conduction)}

The thermal response of both the telescope structure and M1SS during the three days/nights were calculated. The thermal environment data described in section 2.1.2 and the thermal loads presented in sections 2.3.1 and 2.3.2 were utilized to obtain the temperature distributions. The maximum and minimum temperatures calculated for the structure and M1SS at different sample times during the three days/ are shown in the following Table.

Table 2. Thermal response of the telescope and M1SS.

\begin{tabular}{|c|c|c|c|c|}
\hline & \multicolumn{2}{|c|}{ Telescope Temperature } & \multicolumn{2}{|c|}{ M1SS Temperature } \\
\hline & Maximum (o C) & Minimum (o C) & Maximum (ㅇ C) & Minimum (ㄷ) \\
\hline First Day ( $\mathrm{t}=12.5 \mathrm{hrs}$ ) & 5.32 & 0.014 & 3.214 & 1.928 \\
\hline First Night ( $\mathrm{t}=11.5 \mathrm{hrs}$ ) & 2.653 & -1.32 & 2.65 & -1.29 \\
\hline Second Day $(\mathrm{t}=12.5 \mathrm{hrs})$ & 4.38 & -0.505 & 2.842 & 1.079 \\
\hline Second Night $(t=11.5 \mathrm{hrs})$ & 4.09 & 0.17 & 3.69 & 0.59 \\
\hline Third Day $(\mathrm{t}=12.5 \mathrm{hrs})$ & 7.322 & 0.534 & 5.716 & 2.041 \\
\hline Third Night $(\mathrm{t}=11.5 \mathrm{hrs}$ ) & 5.62 & 1.66 & 5.25 & 2.75 \\
\hline
\end{tabular}




\subsection{Thermo-elastic Analysis}

The thermal deformation of the telescope was calculated for both the maintenance/service configuration and the observation configuration using the thermal responses obtained from the 3 day/night heat cycle of continuous operation. From the thermal analyses performed in Cases A and B, the nodal temperature obtained every hour was applied to the horizon-pointing and observation configuration telescope models in order to perform the thermo-elastic analysis. The nodal temperature obtained every hour was used as the heat load in order to obtain the thermal deformation of the telescope. For the thermo-elastic analysis, the structural finite element model created by Empire Dynamic Structures, $L t d$. was utilized. The displacements on the $\mathrm{x}, \mathrm{y}$, and $\mathrm{z}$ directions were constrained at the concrete pier for both daytime and nighttime configurations.

\subsubsection{Thermal Deformation (Daytime/Nighttime Configurations)}

The thermal deformation of the telescope and the primary mirror support structure (M1SS) for the three days/nights and were calculated using the temperature responses at every hour from the combined loads cases described in section 2.1.1. The maximum and minimum displacements obtained for both the telescope structure and M1SS on the $\mathrm{z}$ direction are listed in the following Table.

Table 3. Thermal deformations of the structure and M1SS.

\begin{tabular}{|c|c|c|c|c|}
\cline { 2 - 5 } \multicolumn{1}{c|}{} & \multicolumn{2}{c|}{ Displacement (z direction) } & \multicolumn{2}{c|}{ Displacement (z direction) } \\
\cline { 2 - 5 } \multicolumn{1}{c|}{} & Telescope (max.) & Telescope (min.) & M1SS (max.) & M1SS (min.) \\
\hline First Day (t = 12.5 hrs) & $233 \mu \mathrm{m}$ & $-141 \mu \mathrm{m}$ & $49.4 \mu \mathrm{m}$ & $-97.3 \mu \mathrm{m}$ \\
\hline First Night ( $\mathbf{t}=\mathbf{1 1 . 5} \mathrm{hrs})$ & $433 \mu \mathrm{m}$ & $-993 \mu \mathrm{m}$ & $218 \mu \mathrm{m}$ & $-419 \mu \mathrm{m}$ \\
\hline Second Day ( $\mathbf{t}=\mathbf{1 2 . 5} \mathbf{h r s})$ & $168 \mu \mathrm{m}$ & $-273 \mu \mathrm{m}$ & $117 \mu \mathrm{m}$ & $-57.1 \mu \mathrm{m}$ \\
\hline Second Night (t = 11.5 hrs) & $227 \mu \mathrm{m}$ & $-344 \mu \mathrm{m}$ & $145 \mu \mathrm{m}$ & $-344 \mu \mathrm{m}$ \\
\hline Third Day (t = 12.5 hrs) & $795 \mu \mathrm{m}$ & $-554 \mu \mathrm{m}$ & $94.8 \mu \mathrm{m}$ & $-350 \mu \mathrm{m}$ \\
\hline Third Night (t = 11.5 hrs) & $793 \mu \mathrm{m}$ & $-187 \mu \mathrm{m}$ & $406 \mu \mathrm{m}$ & $-29.5 \mu \mathrm{m}$ \\
\hline
\end{tabular}

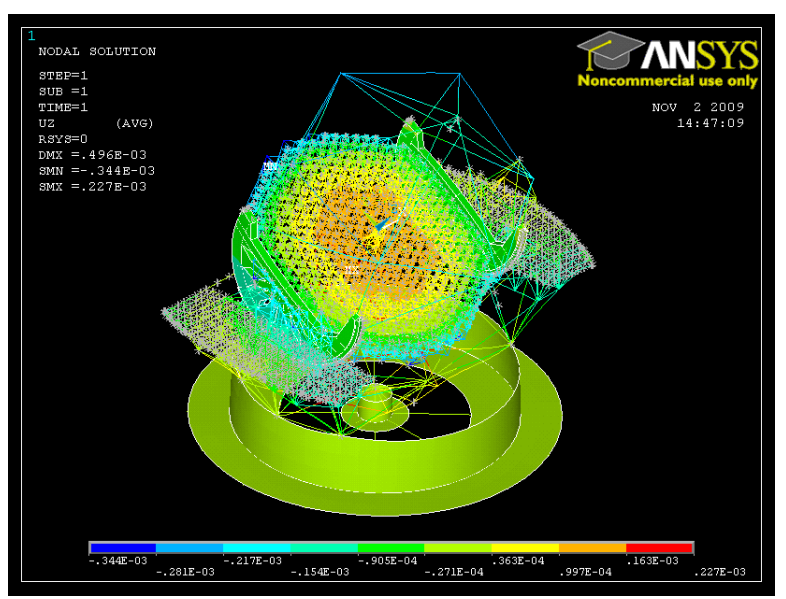

Displacement in Z:

$\max =227 \mu \mathrm{m} ; \min =-344 \mu \mathrm{m}$

Fig. 9.a. Sample Thermal deformation of structure, $t=11.5 \mathrm{hrs}$

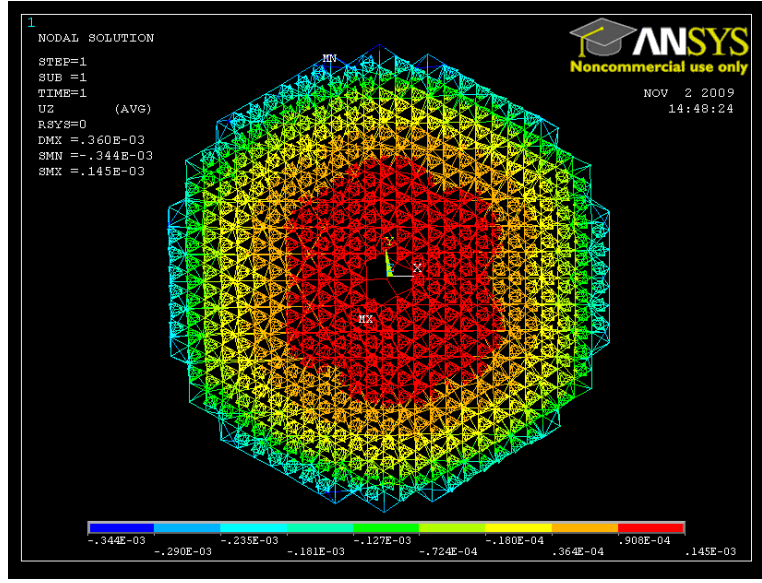

Displacement in Z:

$\max =145 \mu \mathrm{m} ; \min =-344 \mu \mathrm{m}$

Fig. 9.b. Sample Thermal deformation of M1SS, $t=11.5 \mathrm{hrs}$

\section{MERIT FUNCTION CALCULATIONS}

The thermal responses of the telescope structure were demonstrated in the previous chapter including the temperature distribution of each portion of the telescope structure as a function of time over an observing night. Merit function routine (MFR) was implemented for 3 night time hours under the observatory thermal environment conditions using a 3- 
consecutive day at the TMT site. The MFR is a mechanism to integrate a finite element modeling tool with an optomechanical modeling platform which can provide enhanced capabilities to directly calculate the relevant system performance parameters. Current $\mathrm{MFR}^{[12]}$ demonstrates the mathematical basis of these calculations, describes the implementation in ANSYS, MATLAB and ZEMAX, and shows some representative results for the Thirty Meter Telescope structure.

Since telescope behaviors due to thermal impacts are of the main interest in this study, the merit function calculations are based on the Least Square fit algorithm rather than minimizing the maximum stroke motions. In this chapter, typical MFR results are to be discussed in detail for a sample thermal case, the end of the second night. The MFR calculation was made for the 3 night time hours. These results were generated from the structure finite element model Revision 11.3 ${ }^{[11]}$, based on MFR revision 8.2.

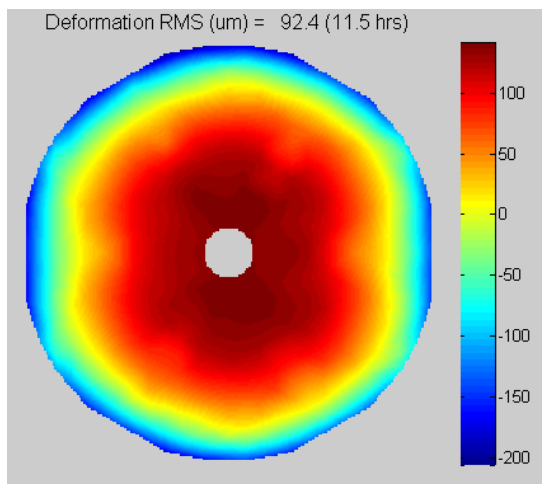

Fig. 10(a). Thermal Deformation in Z-axis (M1-Cell) from FE

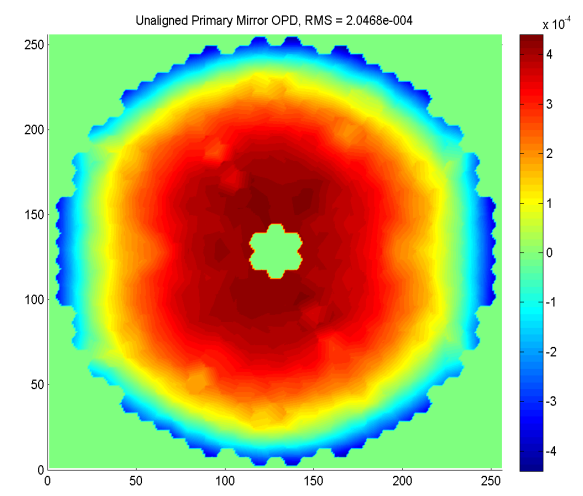

Fig. 10(b). Unaligned M1 segment OPD map

As a sample thermal case, the mechanical deformations and MFR results at the end of the second night are discussed in this section. The deformed shape of the segment support cell was calculated for the sample nighttime case at telescope zenith of 32 degrees. The maximum and minimum deformations of the segment support cell were calculated to be 120 micron and 200 microns along the local z-axis, respectively. The RMS of 93 micron was calculated over the entire primary mirror segments (Figure 10(a)). Based on this deformation, MFR calculates the M1 segment unaligned OPD map. The RMS of 205 microns in OPD was calculated (Figure 10(b), which matches well with the RMS thermal deformation of 93 microns (scale factor of two between the surface error and WFE). MFR also calculates the M1 segment motions and the actuator motions to maintain M1 phasing. The maximum required actuator stroke to maintain M1 phasing was 320 microns. The distribution of required actuator range across the primary mirror for this sample nighttime case was calculated. A positive actuator stroke corresponds to moving the segment away from the sky and its magnitude was measured perpendicular to the mirror surface. Figure 11 shows a histogram of required actuator stroke over the entire primary segments for the same case. This demonstrates the required actuator motions and its magnitude distributions to keep the segment from the thermal deformations.

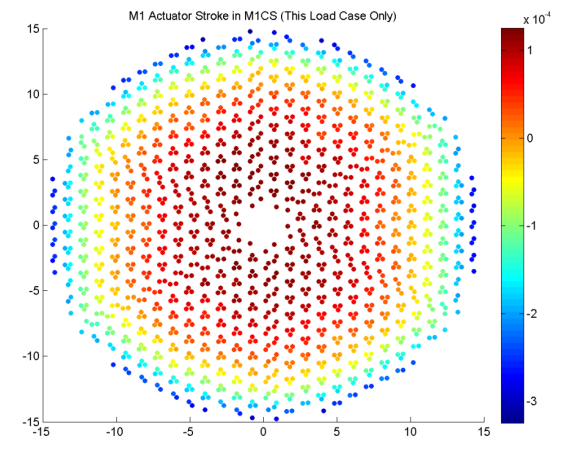

Fig. 11(a). Actuator stroke motion required to maintain M1 phasing

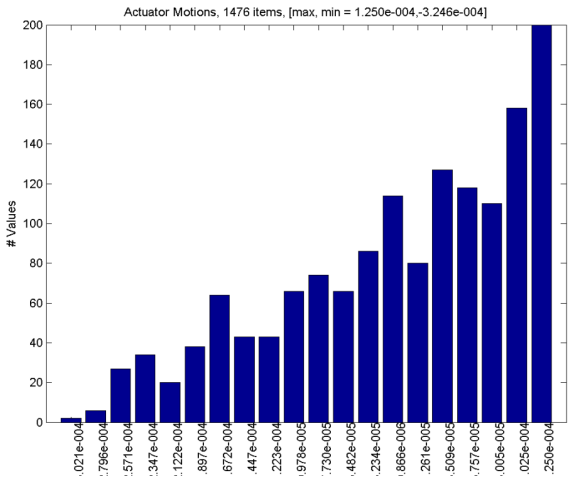

Fig. 11(b). Histogram of actuator stroke motion 
MFR calculates the residual M1 segment motions after re-aligning the optics. The maximum motion of a segment relative to the best fit mirror location is 159 microns decenter with RMS segment decenter of 86.3 microns and the mean of 77.6 microns. MFR also calculates segment rotation clocking motions. The maximum clocking is 9.44E-4 degrees with RMS clocking of 3.74E-4 degrees and the mean of 1.13E-4 degrees. These are the actuator motions to maintain M1 phasing due to thermal responses for the sample nighttime case. The distribution of the segment motions and the relative motion between segments were also calculated. The maximum gap change between segments is 45 microns with a maximum shear, segment motion parallel to gap, displacement of 26 microns.

\section{THERMAL ANALYSIS OF M1 SEGMENT ASSEMBLY (M1SA)}

\subsection{Thermal Loads and Boundary Conditions}

In order to evaluate the thermal response of the segment assembly for a realistic thermal environment, reasonably well defined telescope operation boundary conditions were assumed for the entire segment assembly. Various analyses were conducted in order to estimate the thermal responses and the thermal results Typical thermal conditions include air convection on the front and back surfaces of the segment as well as air convection on the surface of the support hardware component, and heat generation from the actuators and pre-amps of edge sensors. Several operational and service scenarios were considered and the responses were investigated.

\subsubsection{Air temperature variation}

Extensive CFD analyses have been performed to quantify air flows inside the enclosure. Moreover, some simulation schemes have been developed for the air temperature distribution around the optics. For the current analysis, a timedependent air temperature was assumed to have a linear variation. During a 24 hour cycle, the maximum air temperature difference relative to the temperature of the mirror was assumed to be $2{ }^{\circ} \mathrm{C}$ as shown in Figure 12(a). In the analysis over the 24 hour thermal cycle period, the applied temperature loads were assumed to be absolute, rather than a temperature difference between the mirror and ambient conditions. It was further assumed that a time of zero hours indicates sunset or the beginning of night. The air temperature was applied on both front and back surfaces of the segment, the surface of mirror cell components, edge sensors and pre-amps.

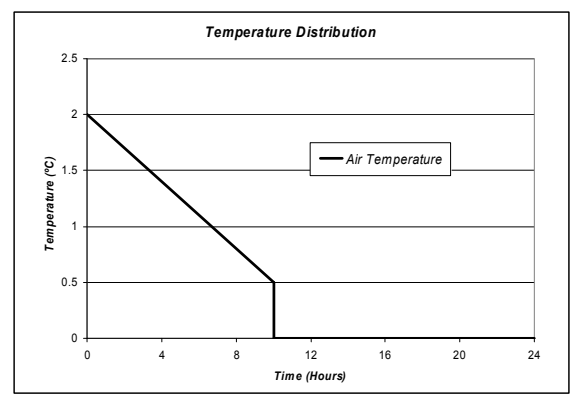

(a)

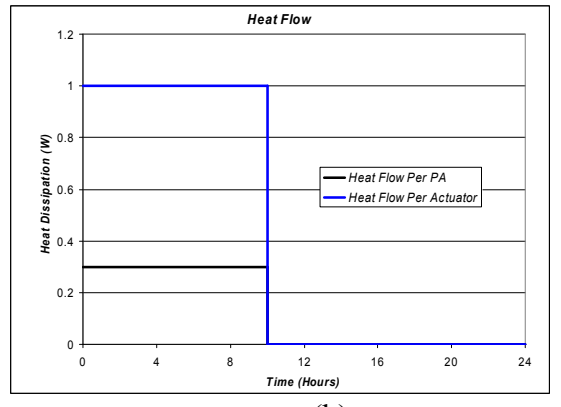

(b)

Fig. 12. Thermal loads, (a) Ambient air temperature profile, (b) Heat flow profiles of pre-amps and cell actuators.

\subsubsection{Heat Generation (Radiation)}

The segment will absorb heat on the back surface due to radiation coming from the three heat generating actuators and the six heat generating pre-amps. The heat dissipated by each of the actuators is $1 \mathrm{~W}$ and the heat dissipated by each preamp is $0.3 \mathrm{~W}$ as shown in Figure 12(b). It was further assumed that the heat flow was constant for the first 10 hours with a maximum of $1 \mathrm{~W}$ for the actuators and $0.3 \mathrm{~W}$ for the pre-amps. The heat sources are equivalent to uniform heat generation rates of $110.2 \mathrm{~W} / \mathrm{m}^{3}$ per actuator and $1128.5 \mathrm{~W} / \mathrm{m}^{3}$ per pre-amp. These six pre-amps were located at 50 percent the distance along the radius and separated by 60 degrees. Currently, the analysis assumes that they are mounted on the back of the mirror segment. However, the pre-amps will be relocated to the segment support assembly (SSA) to reduce the thermal interactions with the mirror segment. 
For the sample scenario thermal case, the following four thermal boundary and loading conditions are considered as:

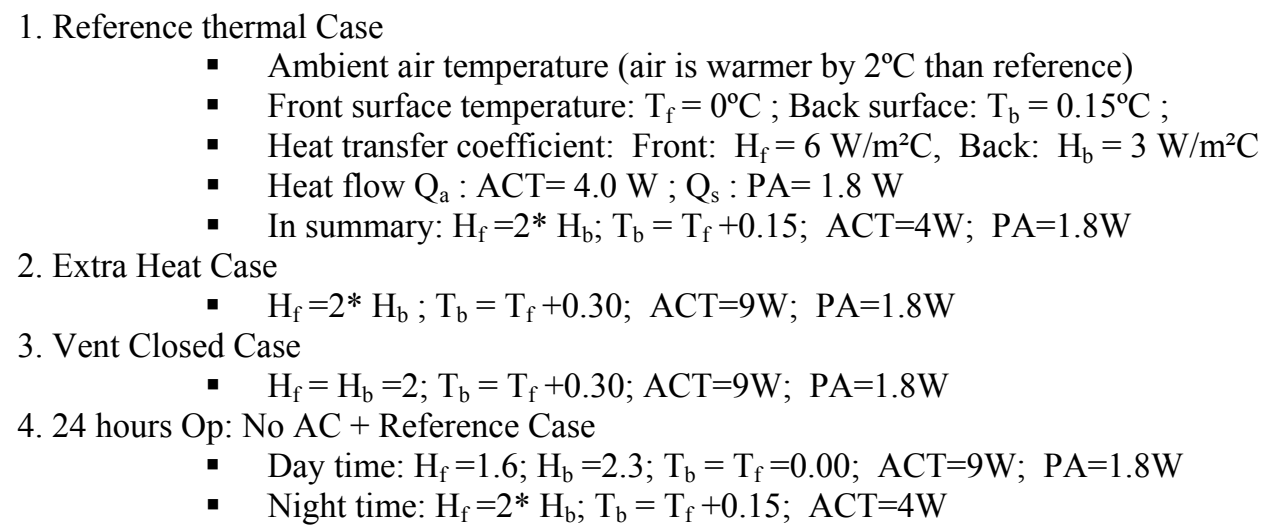

\subsection{Finite Element Models}

In order to calculate the temperature distribution of the TMT M1 assembly, a finite element of the entire mirror assembly was generated using ANSYS. The hexagonal segment was modeled with 4 layers of thermal elements (SOLID70) and shell elements (SHELL57) were created on its front and back surfaces to facilitate the application of thermal loads. In addition, the mirror cell components, the edge sensors, and pre-amps were modeled using thermal elements (SOLID 70). Shell elements (SHELL57) were created on their surfaces, as well, in order to apply thermal loads. Some components in the Segment Support Assembly (SSA) which are not thermally significant were excluded from the FE thermal models for computational efficiency. Finally, a super-element (MATRIX50) was used in order to perform the radiation analysis between surfaces (segment and components). The finite element model used in this analysis is shown in Figure 13(b). By conducting a thermal analysis in ANSYS, the thermal time constant and the temperature distribution for the different cases described in section 2.1 were calculated.

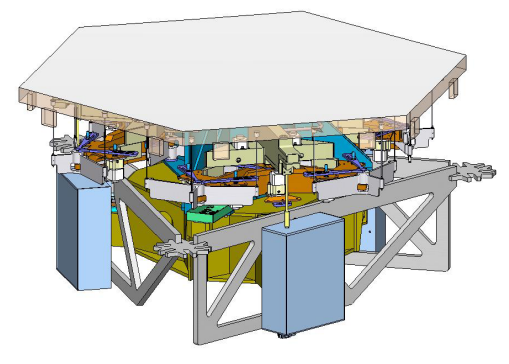

(a)

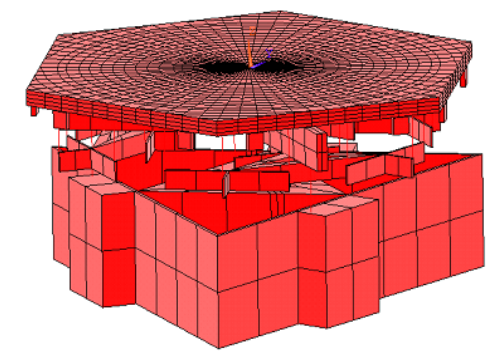

(b)

Fig. 13. M1 and SSA and thermal finite element model. (a) M1 segment and SSA model developed by IMTEC, (b) Segment and SSA thermal FE model

\subsection{Thermal Analysis and Thermo-elastic Analysis}

For the thermal time constant, a convection analysis was performed with a segment thermal FE model. An air convection was applied on the front and back surfaces having heat transfer coefficients of $5 \mathrm{~W} / \mathrm{m}^{2}{ }^{\circ} \mathrm{C}$ and $1 \mathrm{~W} / \mathrm{m}^{2}{ }^{\circ} \mathrm{C}$, respectively. Air convection along the edge of the segment was disregarded. The convection coefficient of $5 \mathrm{~W} / \mathrm{m}^{2}{ }^{\circ} \mathrm{C}$ on the front surface is approximately equivalent to a wind velocity of $1 \mathrm{~m} / \mathrm{sec}$ inside the enclosure based on a CFD analysis. The thermal time constant $(\tau)$ of 5 hours was calculated by obtaining the required time for the mirror to reach $3.7^{\circ} \mathrm{C}$ as $1 / \mathrm{e}$ of the initial temperature at $10^{\circ} \mathrm{C}$. The thermal response of the convection case shows the peak temperature reached 0.97 ${ }^{\circ} \mathrm{C}$ at 6 hours. For the heat generation case, a radiation analysis was performed using the heat flow shown in Figure 12(b). 
Due to radiation, the front surface reached the maximum temperature of $0.45{ }^{\circ} \mathrm{C}$. Detailed thermal responses for both convection and radiation cases were discussed in reference [9].

Moreover, the temperature distribution of the mirror was calculated by combining the thermal loads used in the previous cases (air convection and radiative heat generation). The thermal response was plotted over time using nodes from the front surface and back surface of the mirror positioned at a pre-amp location. The peak temperature responses obtained were $2.21{ }^{\circ} \mathrm{C}$ and $1.30^{\circ} \mathrm{C}$ on the back and front surface, respectively, occurring at 7.5 hours. Therefore, the temperature gradient at the peak response was $0.914{ }^{\circ} \mathrm{C}$ through the thickness of the mirror. The temperature distribution at the peak of the mirror back surface is shown in Figure 14(a). This figure vividly shows the foot-print of six pre-amps in red and three actuators in green. Additionally, the effects of conduction through the rod flexures were investigated. From the radiation analysis it was observed that conduction through the rod flexures was insignificant since their conductive areas are small compared to other components.

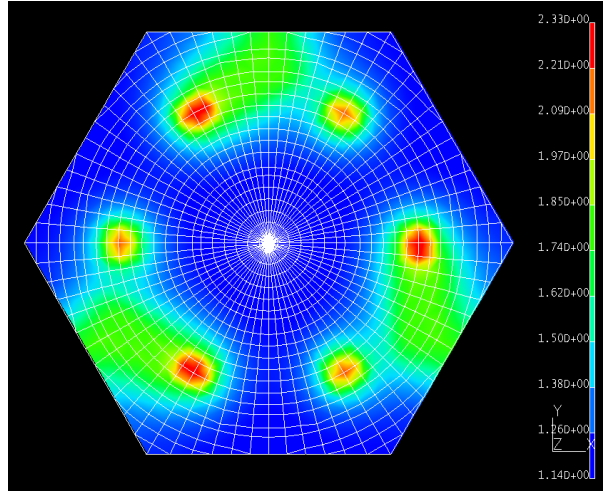

(a)

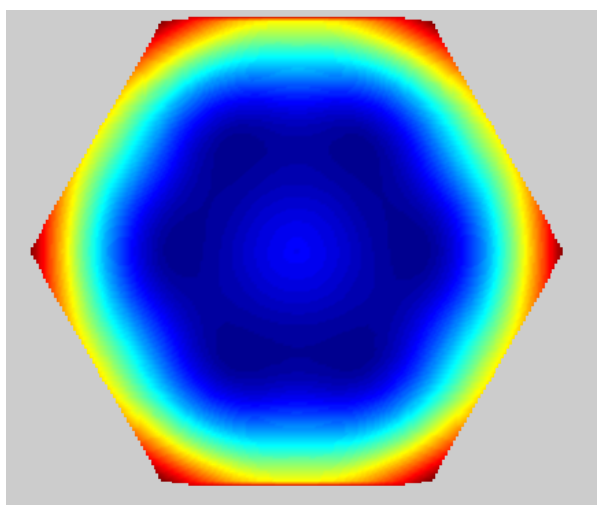

(b)

Fig. 14. Temperature distributions for combined Reference case: (a) Temperature distribution on the mirror back surface at 7.5 hours. (b) Thermal deformation calculated over the entire optical surface before PTF corrections.

The thermal deformation of the hexagonal segment was calculated using the thermal response from the peak temperature during the 24 hour thermal cycle. From the combined thermal loading analysis performed, the nodal temperature at 7.5 hours was applied to the segment model in order to perform the thermo-elastic analysis. Furthermore, the thermal elements in ANSYS, SOLID70 and SHELL57, were converted to structural elements SOLID45 and SHELL41, respectively.

For the thermo-elastic analysis, the model was constrained by three points on the back surface. These supports were located at 67 percent the distance along the radius and separated by 120 degrees. A kinematic 3-point constraint was used for the boundary conditions. From the thermo-elastic analysis the segment deformation was obtained. A peak-valley surface error of $4.6 \mathrm{~nm}$ and RMS surface error of $0.3 \mathrm{~nm}$ was calculated over the optical surface. This optical surface can be further improved by correcting piston, tilts, and focus (PTF) aberrations. This correction can be achieved either by M1 active optics or other compensation Look-Up Table. The optical surface maps of the maximum thermal response before corrections are shown in Figure 14(b). The optical surface RMS error of $0.3 \mathrm{~nm}$ was reduced to $0.1 \mathrm{~nm}$ after corrections.

\section{THERMAL ANALYSIS OF M2 ASSEMBLY (M2CA)}

\subsection{Thermal Loads and Boundary Conditions}

In order to evaluate the thermal response of the secondary mirror, various thermal loads and boundary conditions were considered. Seven thermal environment cases, four unit loads and three combined loads, were performed using a simplified full thermal FE model of the M2 cell assembly (M2CA). This paper addresses the most recent test scenario, Combined boundary conditions with convective heating, constant heat flux. Results for other thermal loads and boundary condition cases are described in more detail in reference [9]. All test environments were performed over a thermal cycle 
period of 24 hours, where a time of zero hours indicates sunset or the beginning of night. Additionally, the applied temperature loads were assumed to be absolute, not a temperature difference between the mirror and ambient conditions.

\subsection{Finite Element Models}

There were three different finite element models utilized for the analysis in ANSYS. The first model was a simple 60 degree wedge of the mirror itself. The second model was an extended version of the first with a simplified cell and support structure, as shown in Figure 15(c). The final variation was a simplified, but complete 360 degree model. It was necessary to simplify the final variation more than the second model due to computational limitations and efficiency due to the increase in element numbers. Based on investigation and the results of the first two models, the following four assessments were made to achieve the final model. First, conduction through the support rods is negligible due to a small cross-sectional area. Additionally, the invar material joining the mirror to the support rods further limits conductive effects. Second, conduction up the sides of the cell wall is negligible due to a high conductive resistance in the direction of heat flow. Third, due to limitations in ANSYS, symmetry conditions are not supported for surface-to-surface radiation; therefore, a 60 degree wedge is not accurate. Lastly, radiation exchange between the cell wall sides and mirror sides is negligible due to the second assumption and the relatively small surface areas of interaction. In other words, convection dominates, and only the area of the mirror's back surface is large enough for radiation to affect mirror performance during operation.

The ANSYS FE models were created using the thermal elements SOLID70, LINK33, SHELL57, and MATRIX50. SOLID70 was used to create the four element mirror layers and the single layer cell frame. LINK33 was used to simulate conduction through the support rods from the cell plate to the mirror's back surface. SHELL57 was used to calculate the view factors between the radiating surfaces. Finally, MATRIX50 was used to implement the calculated view factors and simulate the surface-to-surface radiation effects.

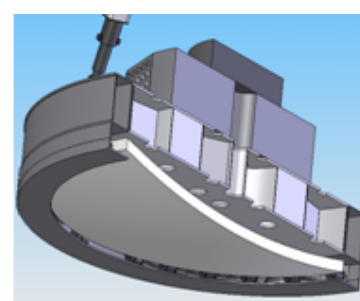

(a)

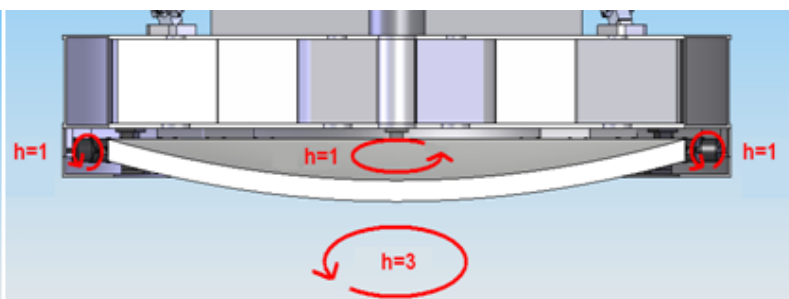

(b)

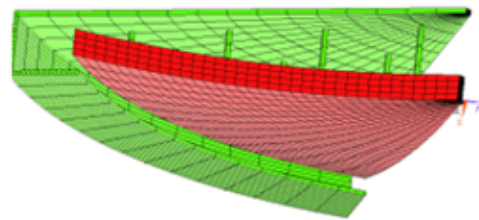

(c)

Fig. 15. Secondary mirror Cell Assembly and an M2CA thermal finite element model. (a) M2 Cell Assembly (M2CA) developed by NOAO - shown in a half model, (b) Thermal boundary - convection coefficients, (c) FE 1/6 model of mirror and support/cell.

\subsection{Thermal Analysis Results}

For the thermal time constant, a convection analysis was performed with the M2 thermal FE mirror-only model. An air convection was applied on the front and back surfaces having heat transfer coefficients of $3 \mathrm{~W} / \mathrm{m}^{2}{ }^{\circ} \mathrm{C}$ and $1 \mathrm{~W} / \mathrm{m}^{2}{ }^{\circ} \mathrm{C}$, respectively. Air convection along the edge of the mirror was incorporated. The thermal time constant $(\tau)$ of 14 hours was calculated by obtaining the required time for the mirror to reach $3.7^{\circ} \mathrm{C}$ as $1 / \mathrm{e}$ of the initial temperature at $10^{\circ} \mathrm{C}$. The thermal response of the latest thermal loads and boundary conditions (mirror with constant heat flux, surface-tosurface radiation exchange, and warm convection) was calculated. The peak occurring at 1.5 hours indicates the exposed front surface temperature is warmer than the back enclosed surface by approximately $0.095^{\circ} \mathrm{C}$. Conversely, the dip at 11.0 hours indicates the back surface is warmer than the front surface by $0.065^{\circ} \mathrm{C}$. It is apparent that the $\mathrm{h}_{1}$ and $\mathrm{h}_{2}$ convection coefficients applied on the M2 surfaces dictates the general shape of the temperature difference. The shape resembles the applied load shown in Figure 12(a), further supporting that convection is the dominant heat transfer mode. Neglecting the edge effects, the temperature delta across the surface is relatively uniform.

The thermal response analysis performed on the TMT secondary mirror was used to obtain a thermo-elastic deformation. The thermo-elastic deformations of interest occur at the point in time of maximum front-to-back surface temperature 
difference. This front-to-back surface temperature difference commonly contributes to the overall focus change of the mirror. Therefore, displacements along the optical axis (the z-direction in the FE models) are of interest for all analyses. The temperature distribution from the latest thermal loads and boundary condition was applied to evaluate the optical thermal deformation. A kinematic 3-point constrained was applied on the secondary mirror around the $20 \%$ radial zone from the center. The maximum z-displacement is $7.2 \mathrm{~nm}$ from the thermal deformation as shown in Figure 16(a). The deflection is in the negative direction, toward the cell structure. This is in agreement with the temperature delta results; the warmer front mirror surface is more expanded than its relatively cooler back mirror surface. The maximum displacement vector magnitude (x-, y-, and z-direction), was found to be $11.3 \mathrm{~nm}$ toward the cell structure. The maximum thermo-elastic response can be further improved by correcting piston, tilts, and focus aberrations. This correction can be achieved either by M2 active optics or other compensation Look-Up table. The optical surface maps of the maximum response before and after the corrections are shown in Figure 16(b) and 16(c) when M2 is at a face up position. The optical surface RMS errors were calculated over the entire optical surface. Before corrections, the maximum peak-tovalley (PV) distance was $7.2 \mathrm{~nm}$ with an RMS error of $2.2 \mathrm{~nm}$. After corrections, the maximum PV distance was $1.2 \mathrm{~nm}$ with an RMS error of only $0.3 \mathrm{~nm}$. The thermal response calculations assume $\mathrm{M} 2$ is at a face up position.

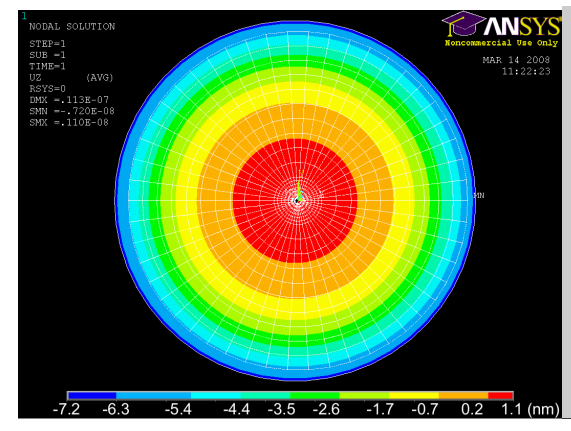

(a)

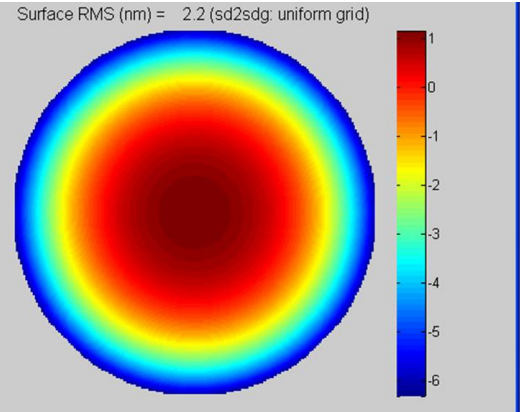

(b)

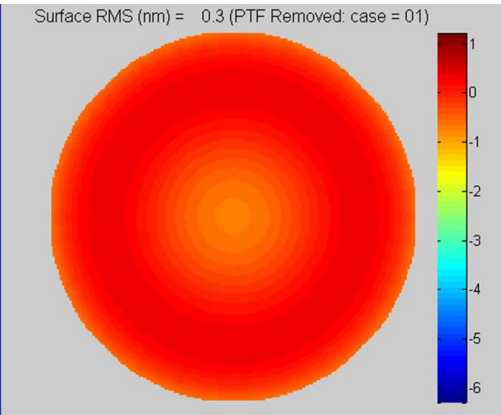

(c)

Fig. 16. (a) thermo-elastic deformation - combined, warm, constant heat flux at 1.5 hours, (b) thermal deformation calculated over the entire optical surface before PTF corrections, (c) the optical thermal deformation after PTF corrections.

\section{THERMAL ANALYSIS OF M3 ASSEMBLY (M3CA)}

\subsection{Thermal Loads and Boundary Conditions}

All thermal loads and boundary conditions applied to the tertiary mirror are the same as those applied to the secondary mirror with a few exceptions. Based on the similarities between the secondary and tertiary mirrors, the analysis was only performed for an extended, simplified tertiary cell model. Details for the boundary conditions and scenarios are described in [5]. It is also important to note that the convection coefficients applied on M3CA follow the same rules as those for M2CA. All participating surfaces enclosed within the cell structure were assigned a convection coefficient of $h=1$ $\mathrm{W} / \mathrm{m}^{2 \circ} \mathrm{C}$ while the exposed front surface was assigned a convection coefficient of $\mathrm{h}=3 \mathrm{~W} / \mathrm{m}^{2 \circ} \mathrm{C}$, which corresponds to a wind speed of $1 \mathrm{~m} / \mathrm{s}$.

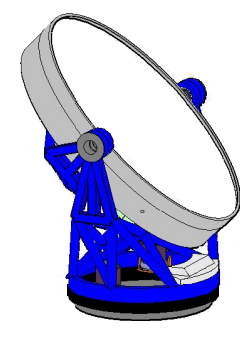

(a)

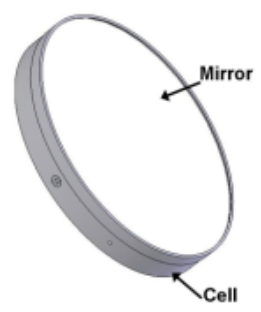

(b)

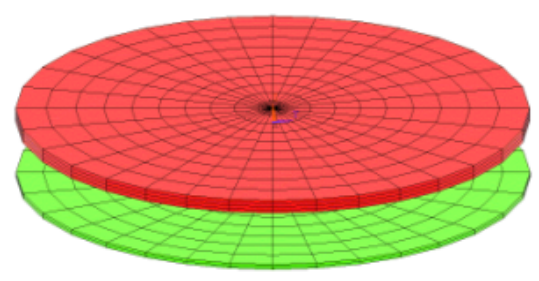

(c)

Fig. 17. Tertiary mirror Cell Assembly and an M3CA thermal finite element model. (a) M3 Cell Assembly (M3CA) developed by NOAO, (b) Thermal FE model of mirror and cell (simplified thermal model). 


\subsection{Thermal Analysis Results}

For the thermal time constant, a convection analysis was performed with a M3 thermal FE model. An air convection was applied on the front and back surfaces having heat transfer coefficients of $3 \mathrm{~W} / \mathrm{m}^{2}{ }^{\circ} \mathrm{C}$ and $1 \mathrm{~W} / \mathrm{m}^{2}{ }^{\circ} \mathrm{C}$, respectively. Air convection along the edge of the M3 was also included. The thermal time constant $(\tau)$ of 14 hours was calculated by obtaining the required time for the mirror to reach $3.7^{\circ} \mathrm{C}$ as $1 / \mathrm{e}$ of the initial temperature at $10^{\circ} \mathrm{C}$.

The latest thermal loads and boundary condition for the tertiary mirror was a combined case of warm convection with constant heat flux and surface-to-surface radiation. Neglecting the edges, which show the highest temperatures due to an added convection effect on the sides, the maximum temperature reached for this test case was approximately $0.57^{\circ} \mathrm{C}$. Additionally, the transient temperature response plots are the same as in the previous section for M2 despite the differences in mirror shape between the M2 and the M3. These results further support that convection, although small, is still the dominant mode of heat transfer.

The temperature difference between the front and back surfaces for the tertiary mirror with warm convection, constant heat flux, and surface-to-surface radiation were obtained. The results are similar to those for the secondary mirror, following the form of the applied warm convection thermal load. The maximum temperature differences are $0.10^{\circ} \mathrm{C}$ at 1.5 hours and $0.045^{\circ} \mathrm{C}$ at 11.5 hours.

\subsection{Thermo-elastic Analysis for Latest Combined Loads}

The temperature distribution from the latest thermal scenario was applied to evaluate the M3 thermal deformation. For the thermo-elastic deformation calculations, the temperature distribution at the point in time of maximum front-to-back surface temperature difference at 1.5 hours was utilized. As with M1SA and M2CA, M3CA also utilized a 3-point kinematic constraint.

The optical surface deformation was calculated. The resulting surface is shown in Figure 18(a) when M3 is at a face up position. The optical surface RMS error of $11.3 \mathrm{~nm}$ was calculated over the entire optical surface. For the 15 -minute field of view (FOV), nine sub-apertures were constructed to simulate the thermal print-through effects over the M3 for the multiple instrument locations. The surface map of each of the nine sub-apertures for the print-through and the RMS surface errors are shown in Figure 18(b). This optical surface error can be further improved by correcting piston, tilts, and focus (PTF) aberrations. Corrections can be achieved either by M3 active optics or other compensation Look-Up table. The optical surface map after corrections is shown in shown in Figure 18(c). This demonstrates that the thermal deformation can be corrected almost entirely by the M3 active optics.

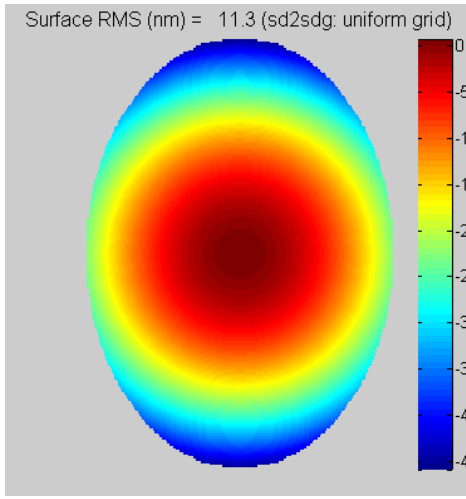

(a)
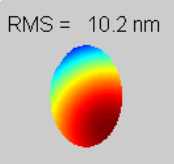

$\mathrm{RMS}=6.9 \mathrm{~nm}$

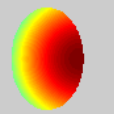

RMS $=10.1 \mathrm{~nm}$

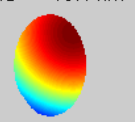

$\mathrm{RMS}=12.5 \mathrm{~nm}$

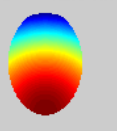

$\mathrm{RMS}=3.3 \mathrm{~nm}$

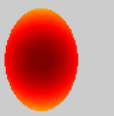

$\mathrm{RMS}=12.4 \mathrm{~nm}$

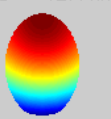

(b)

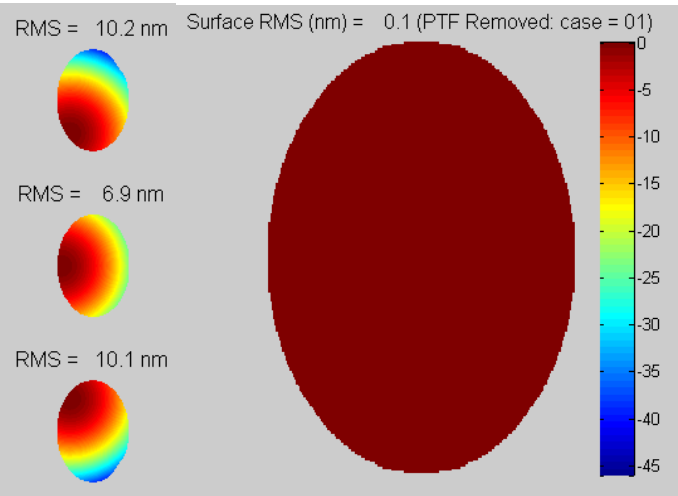

(c)

Fig. 18. M3 deformation at 1.5 hours for the combined case (warm convection, surface radiation, constant heat flux). (a) Thermal deformation print-through calculated over the entire optical surface before PTF corrections, (b) Thermal deformation maps of each of 9 Sub-apertures and RMS surface errors, (c) the optical thermal deformation after PTF corrections. The thermal response calculations assume M3 is at a face up position. 


\section{SUMMARY}

Overall thermal modeling data flow and the interface was addressed as a part of the integrated modeling efforts of the TMT telescope. Temporal and spatial temperature distributions of the telescope structure were calculated under various thermal conditions including air convections, conductions, heat flux loadings, and radiations. A three-consecutive-day thermal environment data was implemented for the thermal analysis and the thermo-elastic analysis was made to predict thermal deformations of the telescope structure at every hour for the three days. A set of 30 key points were identified for the data interface between CFD model and FE models. The ambient air temperatures and convection coefficients in temporal space were spatially mapped over the key points and then further interpolation was employed over the FE models.

Through the thermal response analysis for the telescope, time history responses of the temperature of the M1SS, M2, and M3 for the three nights were calculated. For primary mirror (M1), a typical segment located at a $70 \%$ radius along the local y-axis was considered. These thermal deformation results were translated to a data format which can be further analyzed for the optical performance. Additionally, thermal effects solely from conductions due to heat sources on the telescope structures were calculated. As expected, the conduction response was localized and its impact on the optics is insignificant. The maximum thermally induced M1 motions is about 400 microns, which is much less than the deformation of $2 \mathrm{~mm}$ induced by the gravity. In addition, we calculated the average temperature differences between the telescope parts to accommodate thermal expansion and contraction of the telescope steel structures. The average temperature differences over the entire telescope structure are $1.9^{\circ} \mathrm{C}$ and $3.7^{\circ} \mathrm{C}$ at the end of the second night and the third night, respectively. Merit function calculations under the observatory thermal environment conditions using a 3consecutive day at the TMT site. These MFR calculations are based on a Least Square fit algorithm rather than minimizing the maximum stroke motions. The MFR calculation summary shows the thermal effects are within the error budget.

Table 4. Thermal responses of the TMT optics over three nights

\begin{tabular}{|c|c|c|c|}
\hline & $\mathrm{M} 1$ & $\mathrm{M} 2$ & $\mathrm{M} 3$ \\
\hline $\begin{array}{c}\text { Temperature range } \\
\text { over 3 nights }\end{array}$ & $1 \sim 4^{\circ} \mathrm{C}$ & $-1 \sim 3{ }^{\circ} \mathrm{C}$ & $1 \sim 2{ }^{\circ} \mathrm{C}$ \\
\hline $\begin{array}{c}\text { Temp. rate of change } \\
\text { over night \#2 }\end{array}$ & $0.3^{\circ} \mathrm{C}$ & $0.5^{\circ} \mathrm{C}$ & $0.4^{\circ} \mathrm{C}$ \\
\hline $\begin{array}{c}\text { Deformation } \mathrm{T}_{\mathrm{Z}} \\
\text { over 3 nights }\end{array}$ & $-100 \sim+300 \mu \mathrm{m}$ & $-1000 \sim+600 \mu \mathrm{m}$ & $-50 \sim+300 \mu \mathrm{m}$ \\
\hline $\begin{array}{c}\text { Deformation } \mathrm{T}_{\mathrm{z}} \\
\text { over night \#2 }\end{array}$ & $-50 \sim+20 \mu \mathrm{m}$ & $-600 \sim-50 \mu \mathrm{m}$ & $0 \sim+60 \mu \mathrm{m}$ \\
\hline
\end{tabular}

For the TMT M1 assembly, M2CA, and M3CA, thermal responses from the finite element analysis demonstrated that convection was the most dominant mode of heat transfer, followed by radiation and conduction, respectively. For the TMT M1 assembly as a reference case, the peak thermal response on the mirror under air convection and radiative heat transfer was calculated to be $2.21{ }^{\circ} \mathrm{C}$ at 7.5 hours, along with thermal gradient of $0.914{ }^{\circ} \mathrm{C}$. From a thermo-elastic analysis with the peak thermal loading, a PV surface error of $4 \mathrm{~nm}$ was obtained over the optical surface with an RMS error of $0.3 \mathrm{~nm}$ before performing PTF corrections. After correcting pistons, tilts and focus aberrations, the PV on the optical surface reduced to $1.2 \mathrm{~nm}$ with an RMS error of $0.1 \mathrm{~nm}$. The thermal results of both the M3 and the M2 were very similar. The maximum optical surface displacement of M2 was found at $7.2 \mathrm{~nm}$ with an RMS surface error of $2.2 \mathrm{~nm}$. With M2 active optics, the optical surface PV error was reduced to $1.2 \mathrm{~nm}$ and RMS to $0.3 \mathrm{~nm}$ after piston, tilts, and focus corrections. The tertiary mirror demonstrated greater displacement, reaching maximums of around $49.0 \mathrm{~nm}$ normal to its front surface. With M3 active optics, the optical surface was corrected almost entirely after piston, tilts, and focus corrections.

\section{ACKNOWLEDGMENTS}

This research was carried out at the National Optical Astronomy Observatory, and was sponsored in part by the TMT. The authors gratefully acknowledge the support of the TMT partner institutions. They are the Association of Canadian Universities for Research in Astronomy (ACURA), the California Institute of Technology and the University of 
California. This work was supported as well by the Gordon and Betty Moore Foundation, the Canada Foundation for Innovation, the Ontario Ministry of Research and Innovation, the National Research Council of Canada, the Natural Sciences and Engineering Research Council of Canada, the British Columbia Knowledge Development Fund, the Association of Universities for Research in Astronomy (AURA) and the U.S. National Science Foundation.

\section{REFERENCES}

[1] Mast, T. and Nelson, J., “TMT Image Size and Wavefront Error Budgets Volume 1 2, 3”, TMT.OPT.TEC.07.001, (2007).

[2] Cho, M. and Corredor, A., "TMT M1 Segment Thermal Analysis”, TMT.SEN.TEC.06.034.DRF01, December 12, (2006).

[3] Ponchione, R.J., Ponslet, E., Setoodeh, S., Stephens, V., Tubb, A. and Williams, E., "TMT M1 Segment Support Assembly (SSA) Preliminary Design Review (PDR)”, IMTEC, TMT.OPT.PRE.07.056.REL01, October 24, (2007)

[4] Cho, M. and Corredor, A., "Thermal Analysis of TMT M1 Segment Assembly", TMT.SEN.TEC.08.021.DRF01, December 12, April, (2008).

[5] Cho, M. and Pootrakul, S., "Thermal Analysis of TMT Secondary Mirror Assembly and Tertiary Mirror Assembly,” TMT.SEN.TEC.08.022.DRF01, April, (2008).

[6] Vogiatzis, K., "Advances in Aero-thermal Modeling for TMT", SPIE 7017-29, Marseille, France, (2008).

[7] Schöck, M., Els, S., Riddle, R., Skidmore, W., Travouillon, T., Blum, R., Bustos, E., Chanan, G., Djorgovski, S. G., Gillett, P., Gregory, B., Nelson, J., Otárola, A., Seguel, J., Vasquez, J., Walker, A., Walker, D., Wang, L., “Thirty Meter Telescope Site Testing I: Overview," Publications of the Astronomical Society of the Pacific, Volume 121, issue 878, pp.384-395, (2009).

[8] Dalrymple, N.E., "ATST Primary Mirror Thermal Analysis: Zero-Dimensional, Time-Dependent Model", ATST Project, April, (2002).

[9] Cho, M., Corredor, A., Vogiatzis, K., and Angeli, G., "Thermal Performance Prediction of the TMT Optics", SPIE 7017-43, Marseille, France, (2008).

[10] Cho, M., Corredor, A., Vogiatzis, K., and Angeli, G., "Thermal Performance Prediction of the TMT Structure", SPIE 7427-13, San Diego, California, United States, (2009).

[11] DSL Company, "DSL Telescope Structure Finite Element Model", Revision 11.3, August, (2008).

[12] Roberts, S., "Systems engineering of the Thirty Meter Telescope through integrated opto-mechanical analysis", Proc. SPIE 7738-46, (2010).

[13] Scott Roberts, "MFR Analysis Procedure Document", TMT.SEN.TEC.08.028, (2008).

[14] Vogiatzis, K., "Thermal modeling environment for TMT", Proc. SPIE 7738-11, (2010).

[15] Cho, M., Corredor, A., Vogiatzis, K., and Angeli, G., "Thermal Analysis of the TMT Structure", Proc. SPIE 7738-12, (2010).

[16] Seo, B.-Y., Nissly, C. R., Angeli, G. Z., Ellerbroek, B. L., Nelson, J. E., Sigrist, N., and Troy, M., "Analysis of Point Source Sensitivity as a performance metric for the Thirty Meter Telescope," Proc. SPIE 7017, (2008). 